\title{
Research on Impact of Recommenders and Recommended Information on Consumers' Purchase Intention in Social E-commerce
}

\author{
Ningfei $\mathrm{Xu}$ \\ School of management \\ Wuhan University of Technology \\ Wuhan, China \\ E-mail: xnfphoebe@163.com
}

\author{
Hu Wang \\ School of management \\ Wuhan University of Technology \\ Wuhan, China \\ E-mail: wanghu61@126.com
}

\begin{abstract}
Due to the large number of user recommendations on the social e-commerce platform and the uneven quality, it is important to study what factors influence the purchase intention of users. This paper constructed the model of the user's recommendation to purchase intention from three perspectives: recommender, recommendation information, and information receiver. Based on the theory of trust, a risk theory was introduced to study the role of trust and perceived risk in user recommendation and purchase intention. The results showed that the potential factors that have a direct effect on the purchase intention are trust, perceived risk, professional ability, information quantity, information quality, and visual cues. Based on the results, this study puts forward specific and practical recommendations from the perspective of social e-commerce platform.
\end{abstract}

Keywords-Social e-commerce; consumers' Purchase Intention, risk theory; trust theory

\section{INTRODUCTION}

According to the "China Mobile E-commerce Industry Research Report 2017" released by iResearch, that social online shopping users accounted for $35.2 \%$ of online shopping in 2015, which was an increase of $1.4 \%$ over the previous year. Social sharing shopping gradually becomes a new marketing mode in Mobile E-commerce era. More and more mobile shopping platforms combine shopping and community. At present, there are many social e-commerce platforms at home and abroad. In foreign countries, Thisnext and Pintrest are the representatives, while in China, Xiao Hongshu and Beauty are the representatives. As a new e-commerce model, social ecommerce has created a new wave of combination of sociality and e-commerce. For example, as of May 2017, the number of users of Xiao Hongshu had reached 50 million, and there were approximately 200,000 new users each day. The sales had approached 10 billion yuan. The e-commerce community such as Xiao Hongshu usually forms the community first and then gradually brings consumers to e-commerce. The main content of the community is composed of user-originated content. Other users can make shopping decisions with these user generated contents. In the social e-commerce platform, users often upload their original contents. Users share and communicate through these contents to achieve social functions. The social e-commerce platform focuses on how user recommendations specifically affect other users and translate into shopping flow in order to make better use of these user recommendations. Therefore, this paper studies the factors of user recommendation which impact the consumer's purchase intention in a typical social e-commerce platform. This will provide better advice for optimizing the user recommendations and promoting the user's purchase in the social e-commerce platform.

\section{THEORETICAL BASIS}

The concept of social e-commerce was first proposed by Yahoo in 2005. Although scholars have different explanations for social e-commerce, the general view is still the same. It can be considered that social e-commerce is a derivative model of e-commerce that uses social media to assist the purchase and sale of goods through social interaction and user generated content. In recent years, social e-commerce has an explosive growth trend in the commercial market, but the research on social e-commerce is still at the stage of exploration. At present, research on social e-commerce is mainly focused on consumer behavior, social networking, business model, consumer psychology, and website design. Although the social ecommerce integrates the "socialized" nature of social media, its essence is still 'business". Promoting users' willingness to purchase is the driving force for the continued development of social e-commerce. Nick Hajli showed that social e-commerce can significantly increase consumer trust and purchase intention. In summary, the current domestic and foreign scholars mainly focus on the influence of social factors on trust in social e-commerce and study the influence on purchase intention. When consumers are in shopping process in social ecommerce, in addition to trust, perceived risk also affects the consumer's purchase. Therefore, this study uses trust theory as an intermediary variable and introduces risk theory to study the influence of trust and perceived risk in socialization and purchase intention.

\section{ReseARCH Model AND HyPOTHESES}

\section{A. Professional competence}

The professional competence (PC) of the recommender refers to the ability that the information receiver can perceive that recommender has the correct information. If the 
information receiver perceives that the recommender is knowledgeable in a certain field or has a more comprehensive and profound knowledge of a certain product or service because of his buying experience, the information receiver will reduce the uncertainty of the product or service. If the recommender has high professional competence, consumers tend to believe in the content of such information and then create a purchase intention. Thus, the following hypothesis is made:

H1a: The professional competence of the recommender has a positive impact on trust attitude of the information receiver.

H1b: The professional competence of the recommender has a negative impact on perceived risk of the information receiver.

H1c: The professional competence of the recommender has a positive impact on purchase intention.

\section{B. Tie strength}

The tie strength reflects the degree of social interaction between the two sides of the communication, and refers to the degree of familiarity between the recipient and the sender of the information. It is generally believed that the higher the tie strength is, the higher the consumer's perceived emotional value of the information under the strong relationship is, the lower the risk is, and the higher the degree of acceptance is. Therefore, when making a purchase decision, information from a strong relationship is given greater weight by the consumer. Thus, the following hypothesis is made:

H2a: The tie strength of the recommender has a positive impact on trust attitude of the information receiver.

H2b: The tie strength of the recommender has a negative impact on perceived risk of the information receiver.

H2c: The tie strength of the recommender has a positive impact on purchase intention.

\section{Homogeneity}

Homogeneity (HG) is the degree to which information receivers perceive similar levels of values and interests. The frequency of product information between the two parties with homogenous speeds up, meaning that the individual feels like each other's interests and hobbies are similar to themselves, and communication is more convenient, easier, and free from obstacles. The higher the homogeneity among individuals, the more likely they are to have similar product requirements, which can reduce the risk of purchasing inappropriate products. Thus, the following hypothesis is made:

H3a: The homogeneity of the recommender has a positive impact on trust attitude of the information receiver.

H3b: The homogeneity of the recommender has a negative impact on perceived risk of the information receiver.

H3c: The homogeneity of the recommender has a positive impact on purchase intention. $\square$

\section{Visual cues}

Visual cues (VC) generally refer to the use of pictures, videos, animations, and other visual forms to show the characteristics of a particular product or service. Visual cues are more objective and realistic than the general text form. They show the characteristics such as color, shape and size of the products. Information contains a large number of visual cues are conducive to enhancing consumers' intuitive understanding of the product and reduce risk. Thus, the following hypothesis is made:

H4a: Visual cue of recommendation information has a positive impact on trust attitude of the information receiver.

H4b: Visual cues of recommendation information have a negative impact on perceived risk of the information receiver.

H4c: Visual cue of recommendation information has a positive impact on purchase intention. $\square$

\section{E. Information quality}

The information quality (IQ) reflects the detailed, specific, and true level of information content. There is no uniform standard for consumers to issue recommendation on the social e-commerce platform, so even the recommendations for the same product are not the same. Generally, recommendations can be divided into two categories: one is high quality, and the recommendations are more specific, objective, real, and credible; the other is low quality, and the recommendations are relatively abstract, vague, and emotional. Thus, the following hypothesis is made:

H5a: The information quality of the recommendation has a positive impact on trust attitude of the information receiver.

H5b: The information quality of the recommendation has a negative impact on perceived risk of the information receiver.

H5c: The information quality of the recommendation has a positive impact on purchase intention. $\square$

\section{F. Quantity of information}

The quantity of information refers to the amount of information about a certain product or service. In this study, it mainly refers to the number of recommendations for a certain product or service. In the social e-commerce environment, although interaction and communication are used to establish social network relationships to guide shopping, there are still many uncertainties in nature, and people are often vulnerable to herding effects in situations where they do not understand the uncertain environment. Therefore, as the number of information increases, information receivers perceive more useful information, reduce perceived risk, and enhance trust. Thus, the following hypothesis is made:

H6a: The quantity of recommendation has a positive impact on trust attitude of the information receiver.

H6b: The quantity of recommendation has a negative impact on perceived risk of the information receiver.

H6c: The quantity of recommendation has a positive impact on purchase intention.

\section{G. Impact of trust attitude on perceived risk}

Usually, higher trust will make consumers perceive lower shopping risks, and lower shopping risk will also increase consumers' trust level. Jarvenpaa and Pavlou found that trust can directly affect the attitude of consumers, but also can affect 
perceived risk, and indirectly affect consumer attitudes and purchase intention. Thus, the following hypothesis is made:

H7: Trust attitude has a negative impact on perceived risk of the information receiver. $\square$

\section{H. Impact of trust attitude and perceived risk on purchase intention}

The willingness to purchase is referring to the possibility of a consumer purchasing a product or service. It has a more direct effect on buying behavior than factors such as attitude and emotion. In the virtual shopping environment, trust has become an important factor influencing consumers' purchase intentions because of many uncertainties and risks. As decision makers tend to choose risk-reducing decision-making schemes, perceived risk is also considered to be one of the major factors affecting consumers' willingness to buy. Perceived risk will directly affect the consumer's willingness. Thus, the following hypothesis is made:

H8a: Trust attitude has a positive impact on purchase intention.

H8b: Perceived Risk has a negative impact on Purchase Intention.

The model framework for this article is shown in Figure 1.

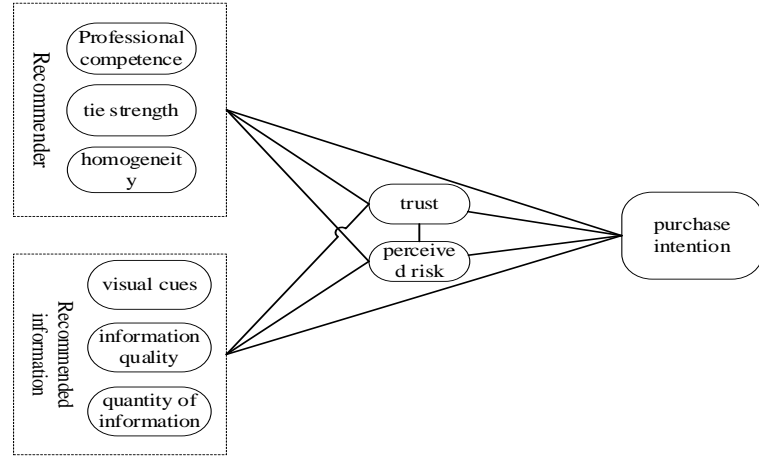

Fig. 1. Model.

\section{Questionnaire Design and Data Processing}

The questionnaire design of this paper is based on the user's recommendation model of consumer purchase intention and related research scales of domestic and foreign scholars. The questionnaire uses Likert's 7-level scale. Number 1 means extremely disagree and 7 means extremely agree.

The questionnaire selects users of typical social ecommerce platforms such as Xiao Hongshu and Meilishuo. Questionnaire was mainly issued on virtual communities of Xiao Hongshu and Meilishuo, such as forums and postal bars. Delete the invalid questionnaire, and finally get 337 valid questionnaires.

TABLE I. ITEMS IN SCALE

\begin{tabular}{|c|c|c|}
\hline Potential Variables & \begin{tabular}{|c|} 
Items \\
\end{tabular} & Reference \\
\hline \multirow{3}{*}{ Professional competence } & The recommender has the expertise of this type of product. & \multirow{3}{*}{ Fei Meng(2012) } \\
\hline & The recommender has rich experience in purchasing and using this type of product. & \\
\hline & Recommenders are very good at picking these products based on personal characteristics. & \\
\hline \multirow{3}{*}{ Tie strength } & I often follow the dynamics of this recommender. & \multirow{3}{*}{ Yaping Chang(2011) } \\
\hline & I often interact with recommenders. & \\
\hline & I sometimes discuss privacy issues with recommenders. & \\
\hline \multirow{3}{*}{ Homogeneity } & I think the recommender is very similar to my personality. & \multirow{3}{*}{ Fei Meng(2012) } \\
\hline & I think the recommender have similar needs with me. & \\
\hline & I think the recommender and my preference are the same. & \\
\hline \multirow{3}{*}{ Visual cues } & There are pictures in the recommendation. & \multirow{3}{*}{ Yang Chen(2013) } \\
\hline & The pictures in the recommendation are clear and easy to identify. & \\
\hline & There is a video in the recommendation. & \\
\hline \multirow{3}{*}{ Information quality } & I think the recommended information is very useful to me. & \multirow{3}{*}{ Chenfeng Lao(2014) } \\
\hline & I think the recommended information content is true and objective. & \\
\hline & I think I can find out what I need from the referral information. & \\
\hline \multirow{3}{*}{ Quantity of information } & Recommended information is liked and collected many times. & \multirow{3}{*}{ Yan Zhang(2013) } \\
\hline & There are many comments under recommendation. & \\
\hline & There are many recommendations for this product when searching for this product. & \\
\hline
\end{tabular}

V. Data Analysis and Model Test

\section{A. Test of Reliability and Validity}

In order to test the reliability of questionnaire, this paper uses SPSS18.0 software to analyze and use Cronbach's Alpha reliability coefficient as measurement index. In general, when Cronbach's Alpha coefficient is greater than 0.7, it indicates that the questionnaire has a good internal consistency. Holistic Cronbach's Alpha coefficient is 0.957, it indicates a good reliability level. Cronbach's Alpha coefficient of potential impact factors is showed in Table 2 . All results are greater than 0.7 , indicating that the reliability of potential variables in the questionnaire is quite good.
TABLE II. RESULT OF TESTING RELIABILITY

\begin{tabular}{|c|c|}
\hline Latent Variables & Cronbach's Alpha \\
\hline Professional competence & 0.896 \\
\hline Tie strength & 0.890 \\
\hline Homogeneity & 0.903 \\
\hline Visual cues & 0.891 \\
\hline Information quality & 0.900 \\
\hline Quantity of information & 0.904 \\
\hline trust & 0.907 \\
\hline perceived risk & 0.901 \\
\hline purchase intention & 0.845 \\
\hline
\end{tabular}

In order to test the validity of questionnaire, this study mainly uses exploratory factor analysis to test the data with SPSS18.0. Before this, we first need to perform KMO test and 
Bartlett sphere test on the sample data to test whether the data can perform factor analysis. The specific values of the test results are shown in Table 3 . The KMO value is 0.917 and the Bartlett's spherical test has a p value of 0.000 . It can be considered that there is a strong correlation between variables and the partial correlation is very weak. It is suitable for factor analysis.

TABLE III. BARTLETT'SSPHERICITY TEST

\begin{tabular}{|c|c|c|}
\hline \multicolumn{2}{|c|}{ Kaiser-Meyer-Olkin metric for sampling enough } & .922 \\
\hline \multirow{3}{*}{$\begin{array}{c}\text { Bartlett's } \\
\text { Sphericity test }\end{array}$} & Approximate Chi-square & 9088.401 \\
\cline { 2 - 3 } & df & 528 \\
\cline { 2 - 3 } & Sig. & .000 \\
\hline
\end{tabular}

\section{B. Test of Model}

\section{1) Model Establishment and Fitting}

This study uses the structural equation method to test the conceptual model of this paper. Using AMOS21.0 software to draw the model diagram, after inputting sample data into the model and run, the verification results of the model can be seen in Table 4. According to the results of each model's adaptability index, the model's overall adaptability index can basically meet the model adaptability requirement, indicating that the model has a good fit.

TABLE IV. FIT RESULT OF MODEL

\begin{tabular}{c|c|c|c|c|c|c}
\hline Fit Index & $\mathbf{X}^{2} / \mathbf{d f}$ & RMSEA & GFI & NFI & CFI & IFI \\
\hline $\begin{array}{c}\text { Fit } \\
\text { Standard }\end{array}$ & $<3$ & $<0.08$ & $>0.9$ & $>0.9$ & $>0.9$ & $>0.9$ \\
\hline Results & 2.153 & 0.059 & 0.851 & 0.899 & 0.942 & 0.943 \\
\hline
\end{tabular}

\section{2) Model Path Analysis}

The coefficient operation results of each path in the model are shown in Table 5 . The $\mathrm{P}$ value in the table indicates significance, *** indicates that the $\mathrm{P}$ value is less than 0.001 , and it can be considered that there is a very significant relationship between these two variables. ** indicates that the $P$ value is less than 0.01 , and when the $P$ value is less than 0.05 , the relationship between the variables is considered to be significant. From the results in the table, it can be seen that the $P$ value between most of the variables meets the condition of more than 0.05, indicating that there is a significant relationship between the variables, and it can be considered that the hypotheses pass the test. The impact of homogeneity on perceived risk is not significant, so the hypothesis $\mathrm{H} 3 \mathrm{~b}$ is rejected. The impact of tie strength on purchase intention is not significant, and the impact of homogeneity on purchase intention is also not significant. The hypotheses H2c and H3c are rejected.

TABLE V. RESULTS OF HYPOTHESIS

\begin{tabular}{|c|c|c|c|c|c|}
\hline $\begin{array}{c}\text { Latent } \\
\text { Variables }\end{array}$ & Hypotheses & $\begin{array}{c}\text { Path } \\
\text { Coefficient }\end{array}$ & P & Significant & Results \\
\hline $\mathrm{PA} \rightarrow \mathrm{TA}$ & H1a & 0.23 & $* *$ & $\mathrm{Y}$ & support \\
\hline $\mathrm{TS} \rightarrow \mathrm{TA}$ & $\mathrm{H} 2 \mathrm{a}$ & 0.78 & $* * *$ & $\mathrm{Y}$ & support \\
\hline $\mathrm{HG} \rightarrow \mathrm{TA}$ & $\mathrm{H} 3 \mathrm{a}$ & 0.34 & $* *$ & $\mathrm{Y}$ & support \\
\hline $\mathrm{VC} \rightarrow \mathrm{TA}$ & $\mathrm{H} 4 \mathrm{a}$ & 0.261 & 0.016 & $\mathrm{Y}$ & support \\
\hline $\mathrm{IQ} \rightarrow \mathrm{TA}$ & $\mathrm{H} 5 \mathrm{a}$ & 0.58 & $* * *$ & $\mathrm{Y}$ & support \\
\hline
\end{tabular}

\begin{tabular}{|c|c|c|c|c|c|}
\hline \multicolumn{6}{|c|}{ Cont. to TABLE IV } \\
\hline $\mathrm{QI} \rightarrow \mathrm{TA}$ & H6a & 0.87 & $* * *$ & $\mathrm{Y}$ & support \\
\hline $\mathrm{PA} \rightarrow \mathrm{PR}$ & $\mathrm{H} 1 \mathrm{~b}$ & -0.36 & $* * *$ & $\mathrm{Y}$ & support \\
\hline $\mathrm{TS} \rightarrow \mathrm{PR}$ & $\mathrm{H} 2 \mathrm{~b}$ & -0.34 & $* *$ & $\mathrm{Y}$ & support \\
\hline $\mathrm{HG} \rightarrow \mathrm{PR}$ & H3b & -0.17 & 0.321 & $\mathrm{~N}$ & $\begin{array}{c}\text { Not } \\
\text { support }\end{array}$ \\
\hline $\mathrm{VC} \rightarrow \mathrm{PR}$ & H4b & -0.39 & 0.003 & $\mathrm{Y}$ & support \\
\hline $\mathrm{IQ} \rightarrow \mathrm{PR}$ & H5b & -0.32 & $* * *$ & $\mathrm{Y}$ & support \\
\hline $\mathrm{QI} \rightarrow \mathrm{PR}$ & H6b & -0.23 & 0.013 & $\mathrm{Y}$ & support \\
\hline $\mathrm{TA} \rightarrow \mathrm{PR}$ & H7 & -0.44 & $* * *$ & $\mathrm{Y}$ & support \\
\hline $\mathrm{PA} \rightarrow \mathrm{PI}$ & H1c & 0.47 & $* * *$ & $\mathrm{Y}$ & support \\
\hline $\mathrm{TS} \rightarrow \mathrm{PI}$ & $\mathrm{H} 2 \mathrm{c}$ & 0.18 & 0.128 & $\mathrm{~N}$ & $\begin{array}{c}\text { Not } \\
\text { support }\end{array}$ \\
\hline $\mathrm{HG} \rightarrow \mathrm{PI}$ & H3c & 0.06 & 0.263 & $\mathrm{~N}$ & $\begin{array}{c}\text { Not } \\
\text { support }\end{array}$ \\
\hline $\mathrm{VC} \rightarrow \mathrm{PI}$ & $\mathrm{H} 4 \mathrm{C}$ & 0.04 & $* * *$ & $\mathrm{Y}$ & support \\
\hline $\mathrm{IQ} \rightarrow \mathrm{PI}$ & H5c & 0.14 & $* * *$ & $\bar{Y}$ & support \\
\hline $\mathrm{QI} \rightarrow \mathrm{PI}$ & H6c & 0.36 & $* * *$ & $\mathrm{Y}$ & support \\
\hline $\mathrm{TA} \rightarrow \mathrm{PI}$ & H8a & 0.66 & $* * *$ & $\mathrm{Y}$ & support \\
\hline $\mathrm{PR} \rightarrow \mathrm{PI}$ & H8b & -0.58 & $* * *$ & $\bar{Y}$ & support \\
\hline
\end{tabular}

\section{Model Results Discussion}

According to the analysis results, most hypotheses have passed the test. According to the ranking of impact effects, the potential factors that directly influence the purchase intention are trust, perceived risk, professional ability, information quantity, information quality, and visual cues. Trust and perceived risk have the greatest effect on the purchase intention. It can be seen that the consumer's trust in the information and the recommender influences the purchase intention of consumers to a large extent. At the same time, trust can reduce consumers' perceived risk and increase consumers' willingness to buy. Under the online environment, there is still a lot of uncertainties in traditional e-commerce or social e-commerce, the perceived risk of consumers will greatly increase. Only when consumers have enough trust can they be willing to buy.

From the results of the study, professional competence is the most important factor influencing consumers' purchase intentions in addition to trust and risk. The professional competence largely reflects the recommender's own understanding of the product and the level of professional knowledge. Through the recommended content of the recommender, the consumer can judge the professional competence of the recommender, thereby inferring whether the recommended content is reliable and has a guiding role. Therefore, for consumers, highly-professional recommenders indicate that they have a wealth of product knowledge or experience. Consumers can use their experience to reduce their own risk of unfamiliarity with the product, increase trust, and increase purchase willingness.

The tie strength has a direct impact on trust and perceived risk, but there is no significant impact on purchase intention. The reason for this phenomenon may be that consumers have increased their understanding through interactive interactions on social e-commerce platforms, thereby increasing trust in each other and reducing perceived risks. However, in the online environment, most consumers are still rational, and they will pay more attention to the factors of the product itself. When making a purchase decision, the consumer is more likely to 
consider whether the product is really a good product or whether it really needs the product, not depending on the relationship with the recommender.

The results of the study show that homogeneity has an effect on trust, but there is no significant relationship with perceived risk and purchase intention. The result is probably because the degree of similarity between the recommender and the consumer does not mean that the product is good or bad. Although trust has been increased to a certain extent, the effect of homogeneity on perceived risk is not obvious, and it will not affect consumers' willingness to buy.

\section{CONCLUSIONS}

This article studies the impact of user recommendations on consumer purchase intentions on social e-commerce platforms. First, the definition of social e-commerce and related research at home and abroad are outlined. The mediation variable of perceived risk was added to the model of consumer purchase intention, and research hypotheses were proposed. Data obtained through empirical analysis of questionnaires, proof of concept model is reasonable. The research results show that the recommendation of the social e-commerce platform indirectly influences the purchase intention of consumers through two mediator variables of trust and perceived risk from the perspective of the recommender and the recommendation information.

This study enriches the research on consumers' willingness to purchase under the social e-commerce domain from a theoretical perspective. At the same time, it also proposes the following suggestions for the content and operating model of social e-commerce platforms:

\section{A. Reducing users' perceived risk and improving user trust}

The results of the study show that the path coefficients of trust and perceived risk to purchase intention are 0.66 and -0.58 , which are the two most directly affecting factors. Other factors can influence purchase intention by affecting trust and perceived risk. In the social e-commerce environment, the interaction within the community can increase the trust between members, and then affect the members' purchase behavior. In most virtual communities, community exchanges are based on common interests. Therefore, the social ecommerce platform can help users to establish interest maps through technical and social methods, establish a common circle of interest or topic, use the topics to guide users to participate in discussion and exchange, and create a positive and lively community exchange atmosphere. With the help of naturally formed social circles, it is easier to establish trust among members of the user circle and reduce the risk perception of the virtual community.

\section{B. Excavate recommenders with high professional competence and enhance interaction between users}

The research shows that the path coefficient between professional ability and purchase intention is 0.47 , which is the third largest factor that affects consumers' purchase intention, and the tie strength also affects the user's trust and perceived risk. When the users browse the recommendation information, they pay more attention to the professional competence of the recommender, and they will be more trustworthy for the recommender with strong professional competence, thereby enhancing the users' willingness to purchase. Moreover, the communication between users can not only meet the users' needs for understanding the products, but also bring emotional satisfaction. Therefore, social e-commerce platforms should explore and nurture recommenders with higher professional capabilities. They can use identity authentication to recognize the professionalism of recommenders and give full play to their professional advantages. At the same time, it promotes the interaction between users and recommenders and enhances the trust of users more effectively.

\section{Improve the quality of recommendation information and enrich the form of recommended information}

The user recommendation content is the core of the social e-commerce platform. From the analysis results, several features of the recommendation information will affect the consumer's purchase intention. Therefore, the platform must encourage more users to share shopping strategies and product experiences in the community while maintaining user experience and at the same time enrich the form of recommended contents. A suitable scoring system can be established to give certain weights to information quality, visual cues and other elements with certain rules. The recommender who gives high-rated recommendation information must reward positive policies, to encourage users with many recommended content and high recommended information quality.

\section{REFERENCES}

[1] Dennison G,Bourdage-Braun S, Chetuparambil M.Social Commerce Defined [R] .Research Triange Park,NC:IBM Systems Technology Group,2009.

[2] Lail. Social Commerce-E-commerce in Social Media Context [C ].Proceeding of World Academy of Science, Engineering and Technology. France: Paris, 2010,pp.39-44.

[3] Wu J, Gao S, Mo Z, Tao L. Research on the Innovation of Social Electronic Commerce Model[J]. Information Science, 2014, 32(12),pp.48-52+66. (In Chinese)

[4] Liu H, Zhang X. Analysis of the status quo of social e-commerce research in China: literature research based on CNKI[J]. Modern Information, 2017, 37(02),pp.171-177. (In Chinese)

[5] Fang X, Song G. An Empirical Study on the Influence of Social ECommerce Consumer Trust on Initial Purchase Intention [J]. Ecommerce, 2018(01),pp.53-55. (In Chinese)

[6] Harris L, Dennis C. Engaging Customers on Facebook: Challenges for E-retailers [J].Journal of Consumer Behaviour,2011.10 (6) ,pp.338-346.

[7] Hajli M. Socialcommerce Adoption Model [C].the UK Academy of Information Systems Conference. UK:University of Oxford, 2012,pp.126.

[8] Mahmood Hajli. A research framework for social commerce adoption [J]. Information Management \& Computer Security, 2013,3(21),pp.144154.

[9] Nick Hajli. Social International Journal constructs and consumer's intention to buy [J].International Journal of Information Management, 2015(35),pp. 183-191.

[10] Sun Y, Lu Y, Wei G The influence of social atmosphere on the purchase intention and behavior of friends in group members [J]. Chinese Journal of Management, 2016, 13(9):,pp.1392-1399. (In Chines) 